\title{
VARIABILIDADE ESPAÇO-TEMPORAL DA PRECIPITAÇÃO NA BACIA HIDROGRÁFICA DO RIO MUNDAÚ (PE/AL)
}

\author{
SILVA, Suzana de Araújo - suzana.araujo.upe@hotmail.com \\ Universidade Federal de Pernambuco / UFPE \\ CANDEIAS, Ana Lúcia Bezerra - analucia@ufpe.br \\ Universidade Federal de Pernambuco / UFPE
}

GOMES, Daniel Dantas Moreira - daniel.gomes@upe.br Universidade de Pernambuco / UPE

SOUZA, Werônica Meira de - weronicameira@gmail.com Universidade Federal Rural de Pernambuco / UFRPE

\begin{abstract}
RESUMO: A Bacia Hidrográfica do Rio Mundaú (BHRM), é uma das mais importantes para os estados de Pernambuco e Alagoas no Brasil. Nessa bacia há ocorrências cíclicas de grandes períodos de estiagens e enxurradas severas. Esses fenômenos causam prejuízos de diversos tipos e em alguns casos chegam a causarem óbitos. Este trabalho analisou a variabilidade espaço-temporal da precipitação no período de 1986 a 2016. Verificou-se imensa heterogeneidade na distribuição espacial da precipitação entre os municípios da BHRM. Observou-se que a correlação entre o Índice de Anomalia da Chuva (IAC) e a Oscilação Decadal do Pacífico (ODP) mostrou-se irrelevante. O El-Niño Oscilação Sul (ENOS) não apresentou influência significativa sobre o regime pluviométrico da BHRM. Para o período analisado houve uma leve tendência de aumento da precipitação.
\end{abstract}

PALAVRAS-CHAVE: Precipitação, IAC, ODP, ENOS, Mundaú

SPACE-TEMPORAL VARIABILITY OF PRECIPITATION IN THE HYDROGRAPHIC BASIN OF THE MUNDAÚ RIVER (PE/AL)

ABSTRACT: The Mundaú River Basin (BHRM) is one of the most important for the states of Pernambuco and Alagoas in Brazil. In this basin there are cyclical occurrences of great periods of drought and severe flooding. These phenomena cause damage of various types and in some cases even cause death. This work analyzed the spatio-temporal variability of the precipitation in the period 1986 to 2016. There was an immense heterogeneity in the spatial distribution of precipitation among the municipalities of the BHRM. It was observed that the correlation between the Rainfall Anomaly Index (IAC) and the Pacific Decadal Oscillation (ODP) was irrelevant. The El Niño Southern Oscillation (ENSO) did not present significant influence on the pluviometric regime of the BHRM. For the analyzed period there was a slight tendency of increase of precipitation.

KEYWORDS: Precipitation, IAC, ODP, ENOS, Mundaú

\section{INTRODUÇÃO}

Segundo o International Panel on Climate Change - IPCC, tem-se observado a nível global, um aumento gradual de temperatura no planeta, isso tem gerado uma preocupação pertinente com as ocorrências de eventos extremos de enchentes e secas, registrados em todo o mundo (IPCC, 2014).

Existem discussões sobre as causas desse aumento de temperatura, a nível global, as que divergem entre a responsabilidade antrópica (MARENGO, 2009), e as causas naturais que não dependem do homem, como as manchas 
solares e a erupção de vulcões que ciclicamente ocorrem (MOLION, 2005) ou ainda as causas incertas (TUCCI, 2005).

Nesse sentido, a observação e análise científica a nível global e também local, tem aperfeiçoado e esclarecido de forma crítica e contínua as análises das variabilidades do clima e como isso afeta a humanidade.

Para estudos mais aprofundados é necessário fortalecer o conhecimento a priori com os bancos de dados ao longo de muitos anos para que se possa compreender em que escalas se dão esses ciclos e quais suas origens. Também é fundamental a compreensão de como suas múltiplas facetas se entrelaçam de forma sistêmica (CHRISTOFOLETTI, 1999; BERTALANFFY, 2015).

O Brasil, sendo um país de dimensões continentais, tem diferentes condições climáticas assim como distintos problemas relacionados ao excesso ou escassez hídrica. Atualmente o maior problema é a escassez da qualidade hídrica (MACHADO \& TORRES, 2012), pois mesmo nos lugares onde quantidade de água é suficiente para os distintos usos, sua qualidade é insuficiente para os mesmos.

O Nordeste Brasileiro (NEB), ao longo de séculos, enfrenta problemas de escassez hídrica e muito se tem discutido sobre causas e soluções para lidar com as secas recorrentes que afetam de modo profundo o desenvolvimento econômico e social da população nordestina (ANDRADE, 2005).

Levando em consideração os aspectos climatológicos do NEB, área considerada de alto risco as mudanças climáticas (MARENGO \& DIAS, 2006; MARENGO, 2009), pesquisas têm sido realizadas no intuito de compreender quais fenômenos afetam os sistemas climáticos e o regime de chuvas (UVO, 1998; KAYANO \& ANDREOLI, 2004, 2007, 2009; GONZALES et al. 2013; PAREDES, BARBOSA \& GUEVARA, 2015; NÓBREGA, SANTIAGO \& SOARES, 2016; MARENGO et al., 2018).

Outros trabalhos mais específicos têm trazido importantes contribuições para compreensão do clima desde o litoral, mata, agreste e sertão pernambucanos (SILVA, MONTENEGRO \& SOUZA, 2017; BARBOSA et al., 2016; RODRIGUES et al., 2017; PEREIRA et al., 2017; FERREIRA. et al., 2017); agreste, mata e litoral paraibano (ARAÚJO, MORAES NETO \& SOUSA, 2009; ÁVILA \& BRITO, 2015; ARAÚJO \& DA SILVA, 2011; CHAGAS NETO \& ARAÚJO, 2017), ao litoral cearense (ANDREOLI et al., 2004).

Esses trabalhos locais têm contribuído principalmente no sentido de correlacionar as variabilidades pluviométricas locais, com os sistemas globais, especialmente com o El-Niño/Oscilação Sul (ENOS) e a Oscilação Decadal do Pacífico (ODP) entre outros fenômenos, aplicando índices climáticos e gerando um conhecimento mais aprofundado para a área estudada que pode ser aplicado ao desenvolvimento regional de forma mais profícua.

A Bacia Hidrográfica do Rio Mundaú (BHRM) em análise, está localizada no NEB, entre os estados de Pernambuco e Alagoas. O rio principal perpassa diferentes domínios morfoclimáticos que vão desde a Caatinga até o Litoral.

Ao longo dos anos observados, tem-se registros de ocorrências de grandes enchentes e também períodos de profunda escassez hídrica na BHRM, gerando transtornos de ordem econômica e social. Em alguns casos, as 
enchentes ocasionaram grande quantidade de óbitos da população situada em suas margens, principalmente na Mata alagoana.

Entre os estudos realizados nessa bacia Da Silva (2008; 2009) analisou aspectos climáticos e agroeconômicos, Fragoso Jr., Pedrosa \& Souza (2010) apontaram reflexões sobre a cheia que ocorreu em 2010, Gomes (2014; 2015; 2016), realizou a compartimentação morfométrica e classificou os sistemas ambientais da bacia e França \& Silva (2017), correlacionaram a cobertura vegetal com a vazão do alto curso da bacia.

Esses estudos têm contribuído para uma compreensão maior sobre os sistemas ambientais e climáticos da bacia, mas, também tem demonstrado a necessidade de construção de um banco de dados climáticos que favoreça a análise dos ciclos climáticos em diferentes escalas temporais e espaciais de forma contínua, para que os resultados possam ser aplicados a uma gestão mais eficiente a curto, médio e longo prazos.

Esse estudo objetivou analisar a distribuição espacial e temporal das precipitações entre os anos de 1986 a 2016 na bacia hidrográfica do Rio Mundaú, assim como correlacionar essas variações aos fenômenos globais ENOS e ODP, visando contribuir para a ampliação do entendimento dos sistemas climáticos na região.

\section{METODOLOGIA}

\section{1 ÁREA DE ESTUDO}

A bacia hidrográfica do rio Mundaú está localizada entre em os estados de Pernambuco e Alagoas, possuindo as coordenadas $8^{\circ} 42^{\prime}$ e 9036' de latitude Sul e 36039' e 35047' de longitude Oeste (Figura 1), a bacia ocupa uma área de $4.101,90 \mathrm{~km}^{2}$ e abrange 16 munícipios do Estado de Pernambuco e 17 municípios do Estado de Alagoas (GOMES et al., 2014).

Segundo Alvares et al. (2014), a classificação climática de Köppen (1931), continua sendo a mais utilizada em todo o mundo, por critérios geográficos e climáticos. Conforme essa classificação, o clima da BHRM, se mescla entre os tipos: As (clima tropical com estação seca de verão), Am (clima de monção), Csa (clima temperado húmido com verão seco e quente) e Csb (clima temperado húmido com verão seco e temperado), com predominância do tipo As sobre os demais (Figura 2): 


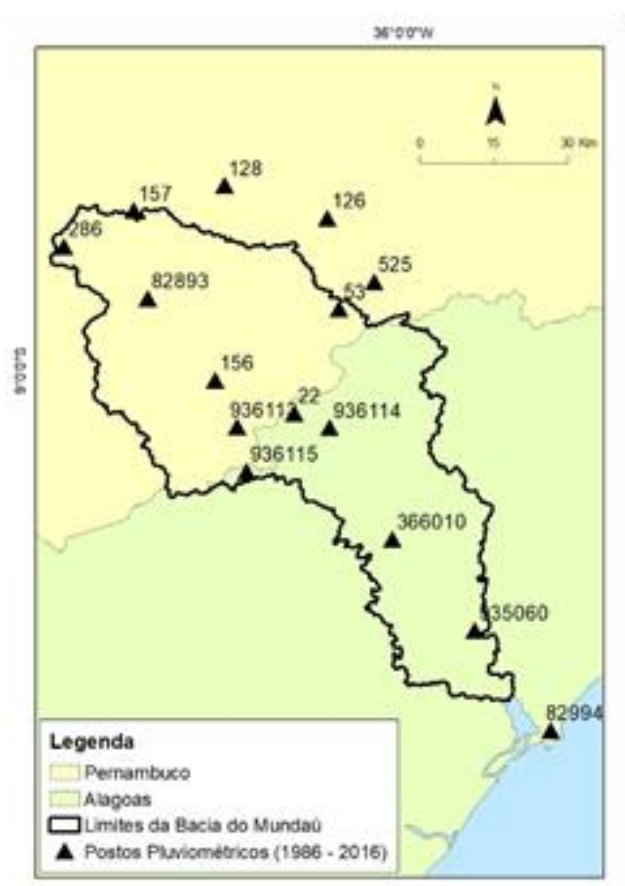

Figura 1- Localização dos postos pluviométricos na BHRM.

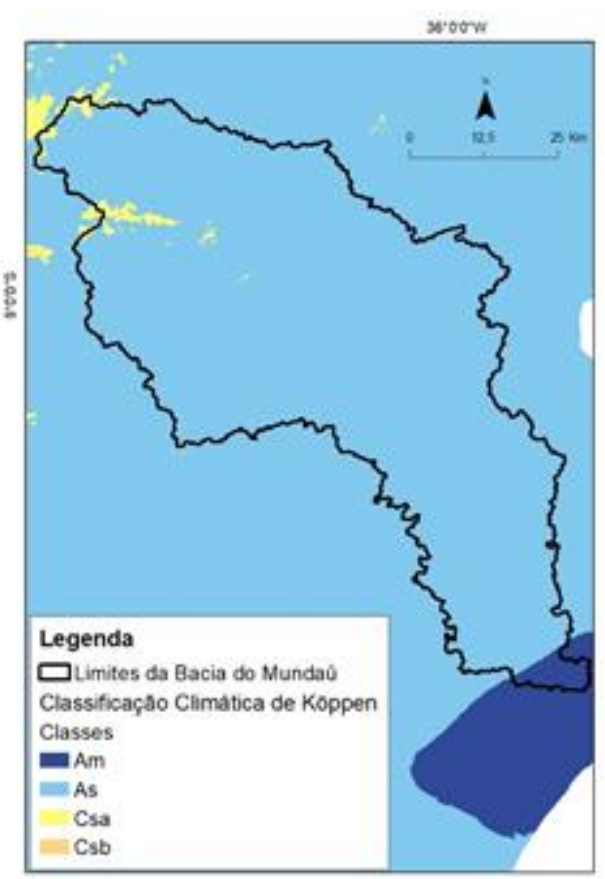

Figura 2- Climas predominantes na BHRM, conforme a classificação de Köppen. Fonte: Alvares et al. (2014).

A bacia hidrográfica do Mundaú apresenta características físicas diferenciadas ao longo de toda sua área. As nascentes do rio principal nascem em região semiárida e perpassa por regiões de Caatinga, Agreste, Mata Atlântica e Litoral. Possui diferentes condições hidrológicas, climáticas, geomorfológicas, fitogeográficas e pedológicas ao longo de todo percurso.

Segundo Gomes (2016), as principais estruturas geológicas que formam a bacia são: Planalto da Borborema; Depressão Periférica da Borborema e Depósitos Sedimentares do Quartenário. Este autor, também classificou os principais tipos de solos da BHRM como: argissolos; gleissolos; latossolos; neossolos litólicos; neossolos regolíticos; planossolos e solos indiscriminados de mangue.

\subsection{DADOS UTILIZADOS}

Foram utilizados nessa pesquisa, dados de precipitação diária, obtidos junto a Agência Pernambucana de Águas e Climas (APAC), Agência Nacional das Águas (ANA) e Instituto Nacional de Meteorologia (INMET), para o período de 31 anos (de 1986 a 2016).

Preliminarmente, foram analisados 45 postos pluviométricos dentro dos municípios que compõem a Bacia Hidrográfica do Rio Mundaú (BHRM), porém destes, apenas 15 postos possuíam dados com uma boa representatividade do período escolhido conforme a Tabela 1, sendo 9 estações em Pernambuco e 6 em Alagoas. Os outros 30 postos foram descartados da análise devido ao grande número de falhas ou longos períodos sem dados. 
Tabela 1 - Postos pluviométricos distribuídos na BHRM e utilizados nessa pesquisa.

\begin{tabular}{cccccl}
\hline UF & Operadora & Código & Latitude & Longitude & Município \\
\hline \multirow{6}{*}{ PE } & APAC & 156 & $-9,01$ & $-36,34$ & Brejão \\
& APAC & 286 & $-8,77$ & $-36,62$ & Caetés \\
& APAC & 53 & $-8,88$ & $-36,11$ & Canhotinho \\
& APAC & 22 & $-9,07$ & $-36,19$ & Correntes \\
& INMET & 82893 & $-8,87$ & $-36,47$ & Garanhuns \\
& APAC & 157 & $-8,71$ & $-36,49$ & Jucati \\
& APAC & 126 & $-8,72$ & $-36,14$ & Jurema \\
& APAC & 128 & $-8,66$ & $-36,33$ & Lajedo \\
& APAC & 525 & $-8,83$ & $-36,05$ & Quipapá \\
\hline \multirow{4}{*}{ AL } & ANA & 366010 & $-9,30$ & $-36,01$ & Atalaia \\
& INMET & 82994 & $-9,65$ & $-35,72$ & Maceió \\
& ANA & 936115 & $-9,18$ & $-36,28$ & Quebrangulo \\
& ANA & 935060 & $-9,47$ & $-35,86$ & Rio Largo \\
& ANA & 936114 & $-9,10$ & $-36,13$ & União dos Palmares \\
& ANA & 936113 & $-9,10$ & $-36,30$ & Santana do Mundaú \\
\hline
\end{tabular}

Fonte: ANA, APAC e INMET.

Segundo Tucci et al. (2014), na ocorrência de falhas, estas devem ser preenchidas por um dos métodos a seguir: a) Método da Ponderação Regional ou b) Método da Regressão Linear.

Optou-se nesse estudo por não aplicar o preenchimento de falhas dos postos pelos métodos acima, devido ao fato da BHRM, apresentar grande diversidade geográfica em sua área (clima, relevo, vegetação e especialmente diferentes médias de precipitação entre um posto e outro em municípios diferentes), o que tornaria o preenchimento de falhas sugerido por Tucci et al. (2014), para essa bacia especificamente, uma falha ainda maior.

O preenchimento de falhas dos postos selecionados foi realizado através da média ponderada dos postos do mesmo munícipio que apresentava dados para o período com falhas, porém não apresentava dados suficientes de toda a série para ser considerado integralmente no estudo.

\subsection{VARIABILIDADE ESPACIAL DA PRECIPITAÇÃO}

Para a distribuição espacial da precipitação foi utilizado o software ArcGis 10.4.1, tendo em posse do modelo matricial (raster) da BHRM, disponibilizado por Gomes (2015), o qual utilizou os dados altimétricos da missão Shuttle Radar Topographic Mission (SRTM), cenas: 08S375ZN, 09S375ZN, 08S36_ZN e 09S36_ZN.

Foram criadas tabelas utilizando o Excel, para inserir os postos pluviométricos através de suas coordenadas (latitude e longitude) no raster e assim poder criar um shapefile (.shp), dos postos pluviométricos. Em seguida também foi criado um shapefile da BHRM, a partir de seu modelo matricial e reprojetados do sistema de coordenadas geográficas WGS 1984 para o sistema de coordenadas planas UTM zona 24S, a qual a BHRM está inserida. 
Para a representação da distribuição espacial da precipitação na BHRM, foi utilizado o método estatístico da Ponderação do Inverso da Distância (Inverse Distance Weighting - IDW) através de ferramentas do ArcGis 10.4.1 e em seguida foram geradas as isoietas para uma melhor visualização desses resultados.

Por fim, obteve-se os mapas da variabilidade espacial da precipitação com médias e totais pluviométricos (anuais e mensais) para o período de 1986 a 2016.

\subsection{VARIABILIDADE TEMPORAL DA PRECIPITAÇÃO}

Para a análise da distribuição temporal da precipitação, os dados de precipitação diária, foram selecionados e organizados numa planilha do Excel e utilizado fórmulas estatísticas para verificar tendências positivas (aumento) ou negativas (redução) da precipitação ao longo do período selecionado.

Também foi realizada a análise da distribuição da precipitação mensal e anual, assim como selecionada a quadra chuvosa (quadrimestre que concentra a maior quantidade de chuva do total anual) e calculada a média e os totais para todos os meses e período (1986 a 2016).

\subsection{1 ÍNDICE DE ANOMALIA DA CHUVA (IAC)}

Para a análise de anomalias da chuva (chuvas acima ou abaixo da média) foi utilizado o Índice de Anomalia da Chuva (IAC). O IAC foi desenvolvido por Rooy (1965), e utilizado por Da Silva (2009), para classificar os anos secos e chuvosos da bacia do Mundaú entre 1955 e 1991.

O IAC faz comparações entre diferentes anos verificando a contribuição da quadra chuvosa para o total anual, tornando claros os mecanismos meteorológicos atuantes. Para calcular o IAC é necessário apenas dados de precipitação e é útil para comparação do desvio da precipitação em relação à condição normal de diversas regiões.

O IAC é representado da seguinte forma:

$$
\begin{array}{cc}
I A C=3\left[\frac{(N-\bar{N})}{(\bar{M}-\bar{N})}\right], & \text { Para anomalias positivas } \\
I A C=-3\left[\frac{(N-\bar{N})}{(\bar{X}-\bar{N})}\right] & \text { Para anomalias negativas }
\end{array}
$$

Sendo: $\mathrm{N}=$ precipitação anual atual, ou seja, do ano que será gerado o IAC $(\mathrm{mm}) ; \quad \overline{\mathrm{N}}=$ precipitação média anual da série histórica $(\mathrm{mm}) ; \overline{\mathrm{M}}=$ média das dez maiores precipitações anuais da série histórica $(\mathrm{mm}) ; \overline{\mathrm{X}}=$ média das dez menores precipitações anuais da série histórica $(\mathrm{mm})$; e anomalias positivas são valores acima da média e negativas, abaixo da média. 


\section{RESULTADOS E DISCUSSÃO}

\subsection{VARIABILIDADE ESPACIAL DA PRECIPITAÇÃO}

Apesar do rio principal da bacia hidrográfica do rio Mundaú ser perene, esta bacia tem sido o cenário de secas dos seus afluentes - afetando a porção setentrional da bacia em Pernambuco e enchentes provocadas por eventos extremos na quadra chuvosa - na região meridional, causando muitos danos materiais e sobretudo de vidas humanas em municípios alagoanos (FRAGOSO JR, PEDROSA \& SOUZA, 2010).

Conforme estudos realizados Fragoso JR. et al. (2014), cheias naturais na BHRM têm causado sérios problemas no estado de Alagoas, tendo nos últimos 100 anos, ocorrido 7 grandes cheias, causando a morte de milhares de pessoas e destruição de patrimônios materiais e imateriais.

Se, na parte setentrional da BHRM (PE) as características geográficas favorecem a escassez hídrica na maior parte do ano, na região meridional ( $A L)$ há excedente hídrico durante todo o ano.

As características do relevo na BHRM, segundo Gomes (2014) podem ser classificadas como sendo: Relevo Plano (5,49\%); Suave Ondulado $(15,83 \%)$; Ondulado (34,61\%); Fortemente Ondulado (33,45\%); Montanhoso $(8,61 \%)$ e Escarpado (2,02\%).

O tipo de relevo predominante na BHRM (Ondulado), favorece um escoamento acelerado, ampliado ainda mais pelo crescente desmatamento da vegetação nativa e a erosão dos solos, provocada entre outros fatores pelo manejo inadequado do solo e práticas rudimentares de agropecuária.

Nos municípios de Pernambuco, onde existem afluentes do rio Mundaú, a maioria das nascentes estão desmatadas e/ou já não possuem mais mata ciliar.

Em alguns casos, como nos municípios de Canhotinho, Caetés e Capoeiras, em Pernambuco, é comum pequenos agricultores desmatarem a vegetação que cresce as margens do rio através da prática de queimadas, para inserir uma agricultura de subsistência, muitas vezes como sua única fonte de renda, ou construir moradias de forma irregular e com alto risco de alagamentos. (SILVA \& SANTOS, 2011).

Esses aspectos geomorfológicos e as práticas antrópicas podem em conjunto com a espacialização da precipitação e sua variação no tempo, explicar a ocorrência de secas ou enchentes na BHRM.

Observando a distribuição espacial da precipitação da BHRM (Figura 3), a medida que se afasta da região litorânea, há uma contínua diminuição das chuvas até atingir municípios que estão inseridos na região semiárida. 


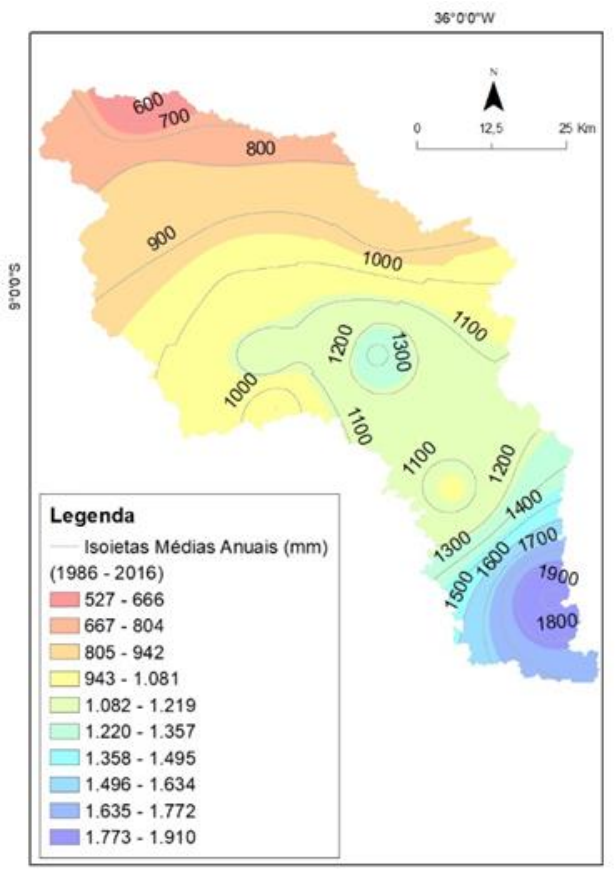

Figura 3 - Precipitações Médias Anuais para a BHRM (1986 a 2016).

Dos 15 postos pluviométricos utilizados, aqueles que estão inseridos no estado de Alagoas possuem maior precipitação média e total anual. Já para aqueles que estão situados no estado de Pernambuco, a precipitação é expressivamente menor.

No primeiro trimestre do ano (Figura 4) as menores precipitações se encontram nas regiões noroeste e nordeste da bacia. Essas regiões em partes estão inseridas no semiárido pernambucano. Os valores mínimos variam em torno de $36 \mathrm{~mm}$ (janeiro), $42 \mathrm{~mm}$ (fevereiro) e $62 \mathrm{~mm}$ (março) respectivamente.

O centro-oeste da bacia apresentou valores um pouco acima da média da região ao redor, com valores variando entre $62 \mathrm{~mm}$ (janeiro), $66 \mathrm{~mm}$ (fevereiro) e $96 \mathrm{~mm}$ (março) (Figuras 4.a; 4.b e 4.c).

Os maiores valores se encontraram próxima a região litorânea do Atlântico no sudeste da bacia, com valores máximos de $80 \mathrm{~mm}$ (janeiro), $81 \mathrm{~mm}$ (fevereiro) e $131 \mathrm{~mm}$ (março).

Observa-se que em fevereiro há um aumento maior das chuvas no extremo noroeste da bacia, enquanto que em março o maior aumento se deu no sudeste com um aumento de mais de $50 \mathrm{~mm}$ precipitados. 

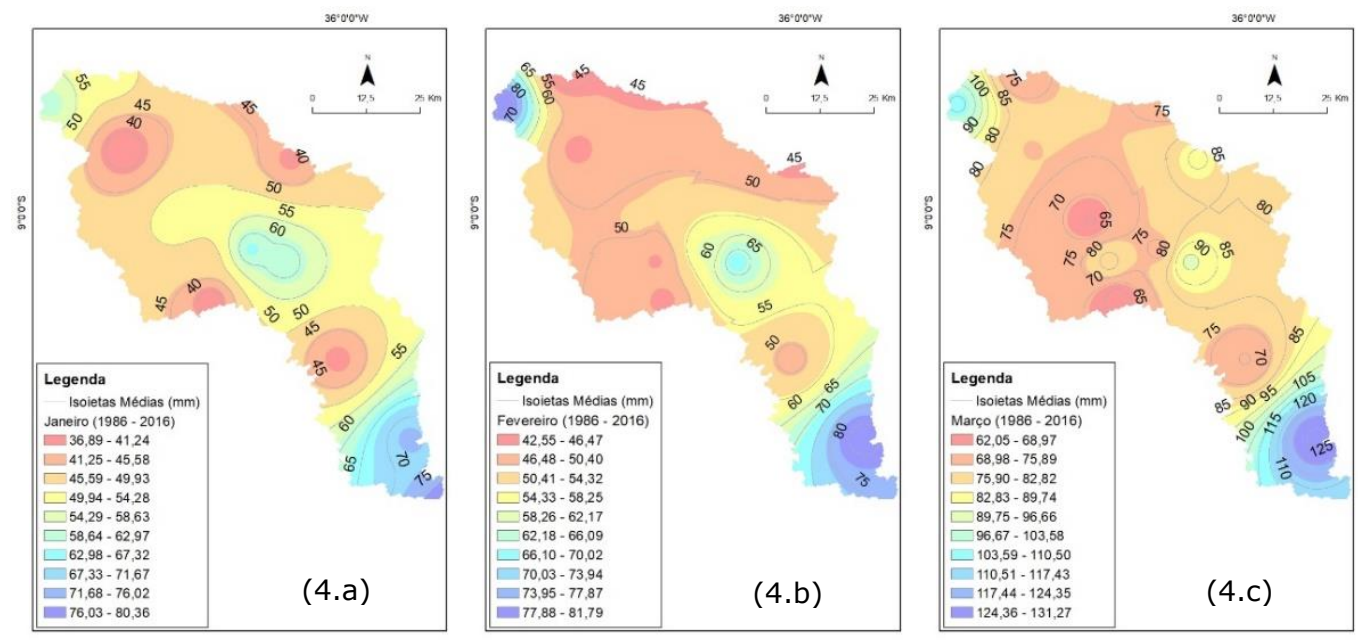

Figura 4 - Precipitações médias do primeiro trimestre. (4.a) Janeiro; (4.b) Fevereiro e (4.c) Março.

É no segundo trimestre do ano (Figura 5), que as chuvas se intensificam na BHRM de modo geral. Este é o trimestre com maiores médias e totais anuais da bacia.

É importante observar que na parte noroeste da bacia em abril (Figura 5.a) e maio (Figura 5.b), chove menos do que em março (Figura 4.c), sendo o oposto em todo o restante da bacia. Possivelmente essa região recebe influência nesse período (março) de fenômenos, que não atingem o sudeste da bacia.

Em abril as chuvas variam entre $68,39 \mathrm{~mm}$ no extremo noroeste à $224 \mathrm{~mm}$ no sudeste da bacia. O aumento prevalece ainda em maio, atingingo seus máximos em junho que é o mês que apresenta os maiores picos da BHRM, assim como aquele onde há mais probabilidade de ocorrência de desastres causados por cheias.

Junho (Figura 5.c), atinge sua máxima precipitação na zona da mata alagoana no sudeste, onde ocorre valores acima do chovido no litoral alagoano, com uma média anual máxima de $348,81 \mathrm{~mm}$ e mínima de $76,84 \mathrm{~mm}$ na região semiárida pernambucana.

Já na região agreste da bacia, localizada no centro-oeste da BHRM, as máximas precipitações também ocorrem em junho com valores médios de $220 \mathrm{~mm}$. 

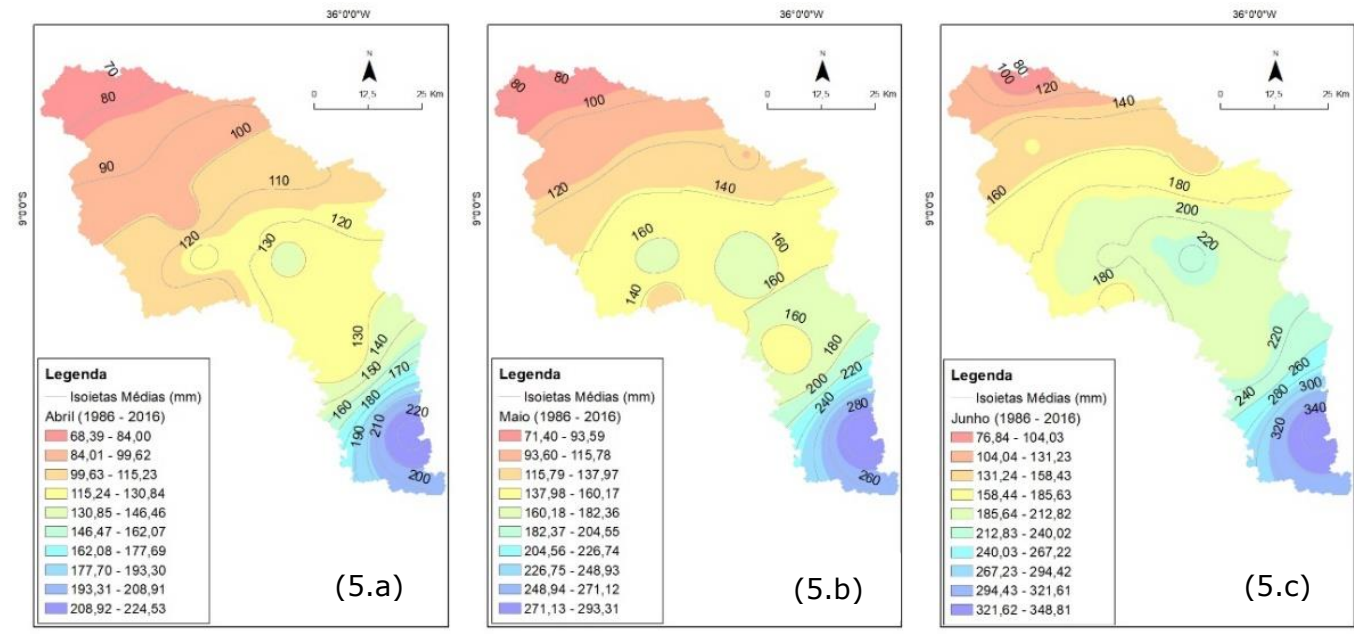

Figura 5 - Precipitações médias do segundo trimestre. (5.a) Abril; (5.b) Maio e (5.c) Junho

O mês de julho (Figura 6.a) é o segundo mais chuvoso do ano, ficando atrás apenas de junho, de modo geral ele contribui de forma valiosa para o total anual da bacia. Sua precipitação mínima é de $70,50 \mathrm{~mm}$ e sua máxima é de 301,75 .

Já em agosto (Figura 6.b), as chuvas começam a reduzir na bacia havendo uma redução em torno de $100 \mathrm{~mm}$ das precipitaçãos máximas, comparando ao mês anterior.

Em setembro (Figura 6.c), a redução é brusca, havendo uma redução de cerca de $50 \%$ com relação a agosto, com valores mínimo de $23,50 \mathrm{~mm}$ e máximo de $113,35 \mathrm{~mm}$.
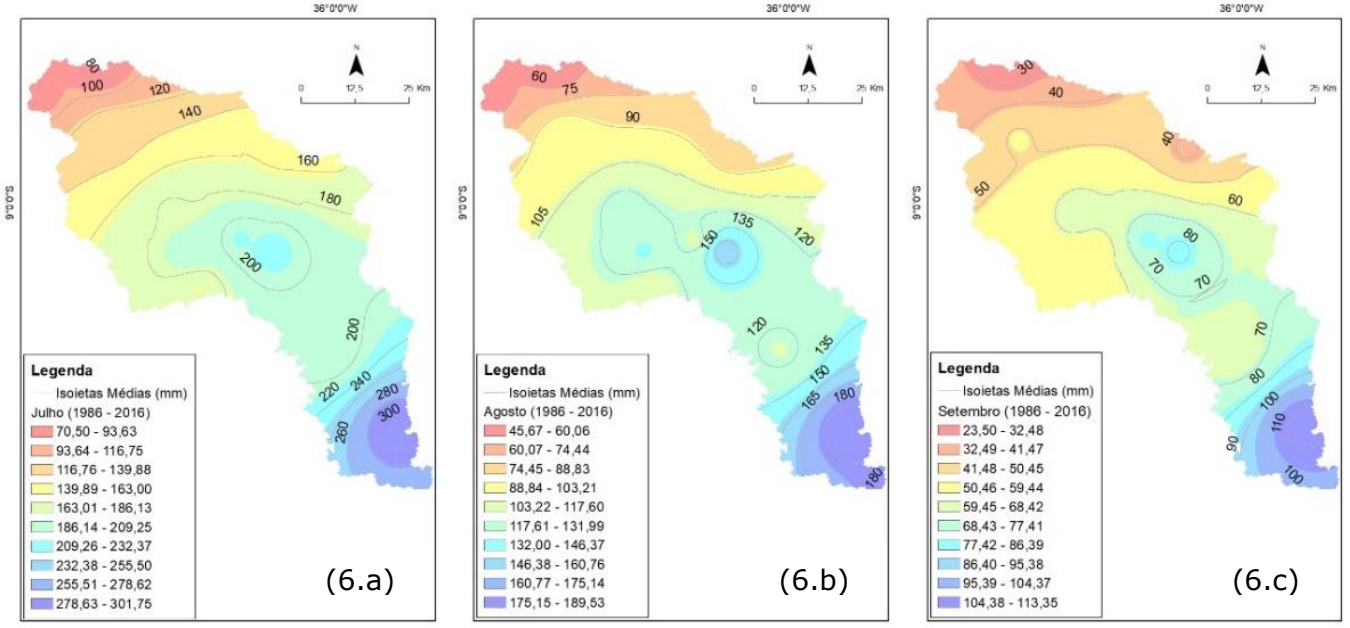

Figura 6 - Precipitações médias do segundo trimestre. (6.a) Julho; (6.b) Agosto e (6.c) Setembro. 
O trimestre mais seco da BHRM é o último: outubro (Figura 7.a), novembro (Figura 7.b) e dezembro (Figura 7.c). O mês de novembro especialmente, é aquele que historicamente apresentou as menores precipitações médias em Pernambuco, o que contribuiu para a menor média mensal de toda a bacia. Na região semiárida esse valor chega a $11,52 \mathrm{~mm}$ precipitados, podendo causar sérios problemas de escassez hídrica.

Já o mês mais seco do ano para a região sudoeste e sudeste da bacia, em Alagoas, é o mês de dezembro com valor máximo nessa região de $36 \mathrm{~mm}$. No centro-oeste da bacia, região agreste os valores são menores que no semiárido, chegando a 22,57mm em média.
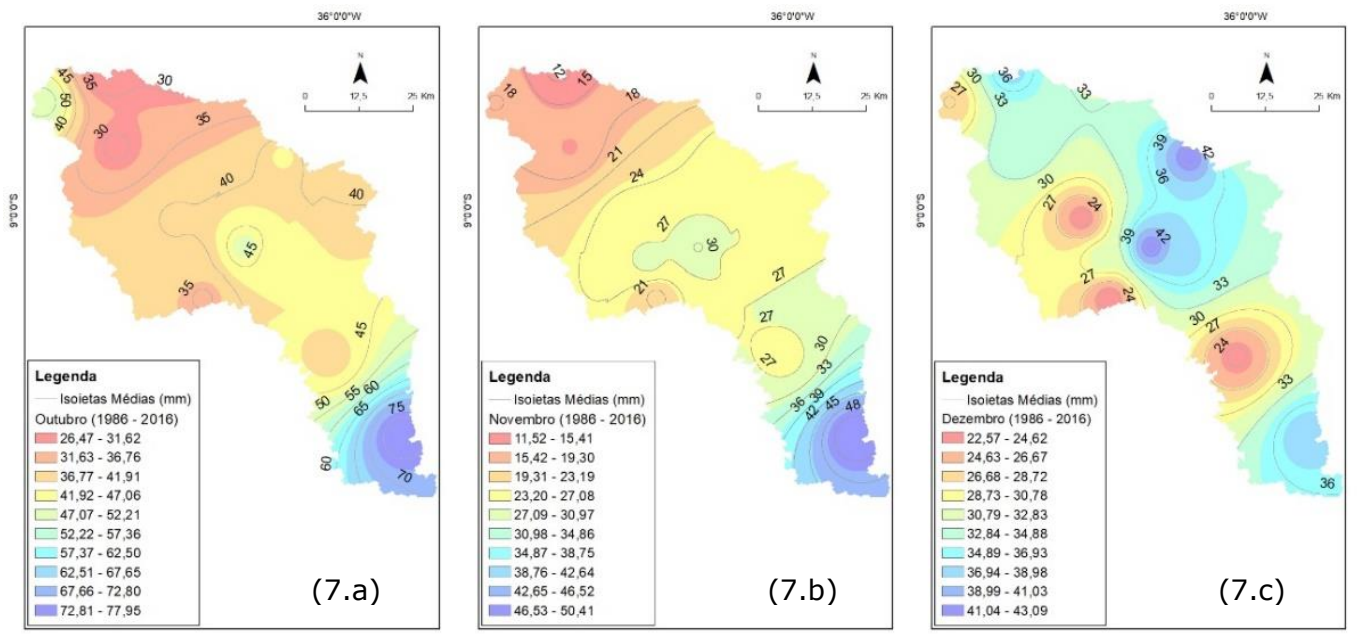

Figura 7 - Precipitações médias do terceiro trimestre. (7.a) Outubro; (7.b) Novembro e (7.c) Dezembro.

Na Figura 8, podemos observar a média dos quadrimestres da BHRM e compará-los. O quadrimestre mais chuvoso do ano é o segundo, correspondendo aos meses de maio, junho, julho e agosto (Figura 8.b).

Este quadrimestre é especialmente favorável para o armazenamento de água nos reservatórios pernambucanos, assim como para a recarga dos lençóis freáticos em toda a bacia. É também o quadrimestre que de certo modo determina, conforme a quantidade de chuva precipitada, se os pequenos produtores rurais terão resultados satisfatórios ou insuficientes, economicamente falando, no agreste pernambuco.

Segundo o Plano Diretor de Recursos Hídricos da BHRM (CONSULTORIA TÉCNICA LTDA.,1999), as atividades de uso e ocupação da terra da BHRM, que predominam em Pernambuco é a agropecuária, cobrindo $70,4 \%$ da área da bacia, enquanto que em Alagoas, são as atividades agrícolas de cana-de-açucar que predominam, correspondendo a $21,76 \%$ da área da BHRM.

Como já citado antes, a BHRM têm como base de sua economia as culturas agropecuárias. Em Pernambuco esse quadrimestre é essencial para os pequenos agricultores, que em sua maioria não utilizam técnicas de irrigação e dependem diretamente das condições climáticas para sua safra ou criação de animais (bovinos, aves, caprinos e suinos). Em anos em que a precipitação 
desse quadrimestre é baixa, os municípios pernambucanos, podem ter sua economia drasticamente afetada, chegando em alguns casos ao estado de "emergência", por escassez hídrica.

Já no estado de Alagoas, o segundo quadrimestre representa de modo geral a expectativa de enchentes em vários municípios localizados as margens do rio Mundaú, como Rio Largo, Santana do Mundaú, União dos Palmares, Quebrangulo entre outros. Esses e outros municípios alagoanos, têm históricos de enchentes e alagamentos nesse quadrimestre, principalmente no mês de junho, onde ocorreram os maiores prejuízos causados pela chuva. A construção de reservatórios grandes na parte pernambucana, em parte auxília na resolução de ambos os problemas entre os estados, mas, somente isso não é suficiente para resolver os problemas.

Em pesquisa realizada por Oliveira, Souza \& Fragoso Jr. (2014), os autores analisaram o histórico de enchentes ocorridas na BHRM e na Bacia Hidrográfica do Rio Paraíba do Meio - que faz fronteira com a do Mundaú, e juntas desaguam suas águas no Complexo Estuarino-Lagunar Mundaú-Mangaba (CELMM) em Alagoas, especialmente a cheia ocorrida em junho de 2010, onde os desastres foram tão impactantes principalmente nos municípios alagoanos, que além de ser amplamente noticiado em todo o Brasil, os prejuízos trouxeram consequências que são sentidas até hoje na área afetada.
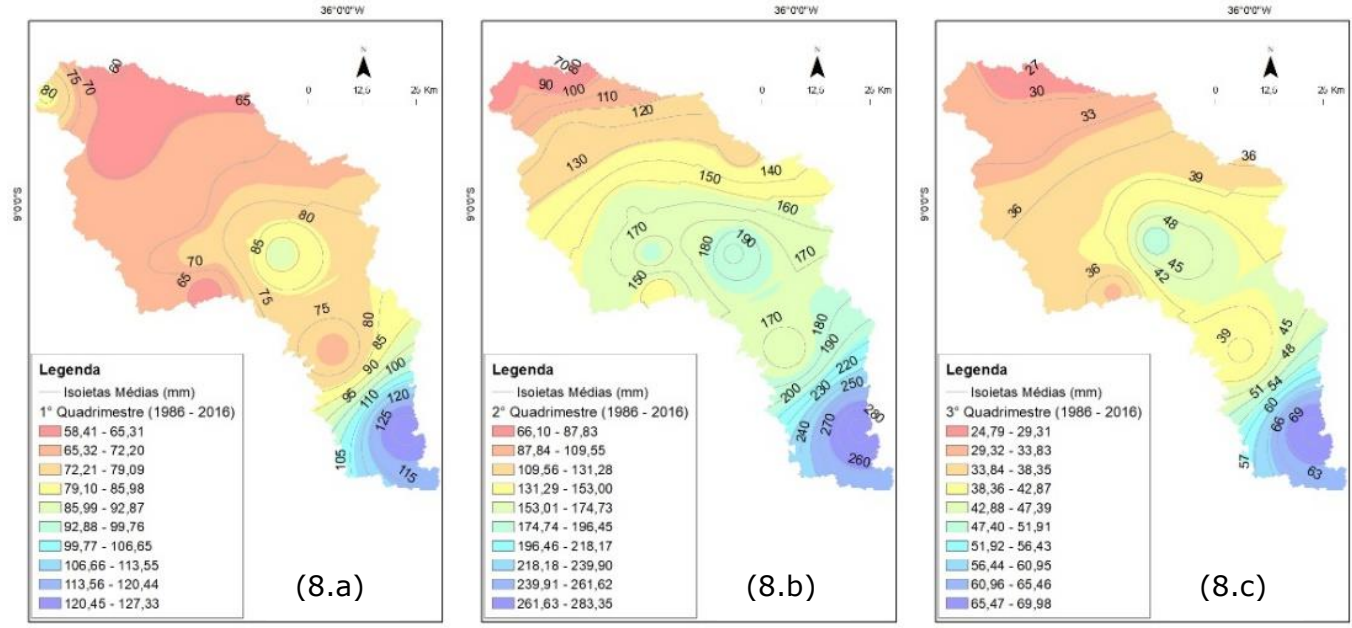

Figura 8 - Precipitações médias quadrimestrais. (8.a) Média do Primeiro Quadrimestre; (8.b) Média do Segundo Quadrimestre e (8.c) Média do Terceiro Quadrimestre

Segundo Oliveira, Souza e Fragoso Jr. (2014), ocorreram cinco grandes cheias (que se tem registros), na BHRM e na Bacia Hidrográfica do Rio Paraíba do Meio (nos anos de 1969; 1988; 1989; 2000 e 2010). O total de óbitos decorrentes dessas cheias, segundo esses autores, foram de 1.281 , o total de casas destruídas ou danificadas foram de 56.734 e o total de pessoas afetadas foram de 338.347 até a cheia de 2010 .

Sobre o primeiro quadrimestre do ano (Figura 8.a), correspondente aos meses de janeiro, feveiro, março e abril, pode-se afirmar que é o segundo mais chuvoso. Na BHRM é a partir de abril que se inicia o ano hidrológico. Também durante esse período ocorrem chuvas fortes e repentinas em várias regiões da 
BHRM, especialmente nos municípios próximo ao litoral alagoano, como Rio Largo e Macéio.

Já o terceiro quadrimestre: setembro, outubro, novembro e dezembro, (Figura 8.c) é o mais seco, da BHRM, onde boa parte da população recorre aos reservatórios, para satisfazer seus diversos usos e consumos, devido ao fato da maioria dos afluentes do rio Mundaú serem intermitentes, começando a reduzir sua vazão a partir de agosto.

Nos municípios pernambucanos, em anos muito secos, ainda ocorre a prática de abastecimento por carros-pipa, ou seja, naqueles municípios que não possuem reservatórios com boa capacidade de abastecimento como Caétes e Capoeiras que se deslocam para os municípios mais próximos, como Garanhuns visando abastecer a população local ou dessedentar seus animais.

Em Garanhuns foi inaugurado o reservatório Cajueiro (ou Mundaú II) em agosto de 2010, com capacidade de armazenamento de 14,5 milhões de metros cúbicos, para fortalecer o abastecimento do município e serviu de suporte para 0 abastecimento de municípios vizinhos nos períodos de escassez hídricas.

Antes da construção do reservatório Cajueiro havia os reservatórios Mundaú (em Garanhuns) e Inhumas (no município de Palmeirina), porém ambos se tornaram limitados para abastecimento, devido o aumento populacional e a eutrofização das águas do reservatório Mundaú.

A eutrofização do reservatório Mundaú tornou suas águas inadequadas para o abastecimento e onerosas para o tratamento. É importante ressaltar que a construção do reservatório Cajueiro em Garanhuns, também teve um papel fundamental para evitar que ocorressem cheias tão danosas a municípios alagoanos, como a que ocorreu em 2010, além de ampliar o abastecimento, o que foi duplamente importante para toda a BHRM.

\subsection{VARIABILIDADE TEMPORAL DA PRECIPITAÇÃO}

As variabilidades climáticas naturais que afetam o regime pluviométrico global, podem ser definidas, de modo geral em variabilidades anual (ou sazonal), interanual, decenal e multidecenal.

São variações que podem ser observadas em séries históricas da precipitação, são recorrentes e podem afetar positivamente ou negativamente a quantidade de água precipitada numa bacia hidrográfica, assim como também caracterizam a ocorrência de anos muito chuvosos ou muito secos.

Analisando o variabilidade anual das chuvas na BHRM (Figura 9), têm-se no mês de junho a maior média $(186,09)$, seguido por julho $(173,71 \mathrm{~mm})$, maio $(146,23 \mathrm{~mm})$ e abril $(116,35 \mathrm{~mm})$. Já os meses mais secos são novembro $(24,59 \mathrm{~mm})$ e dezembro $(28,87 \mathrm{~mm})$, respectivamente. 


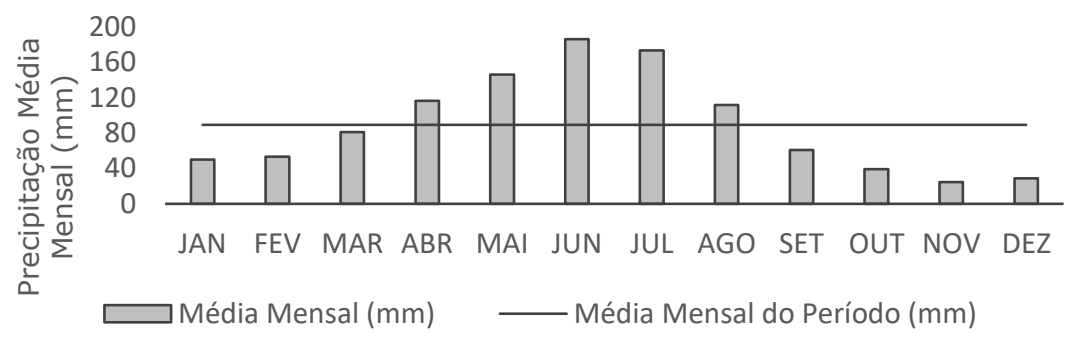

Figura 9 - Precipitações Médias Anuais da BHRM.

A partir da análise dos dados selecionados para a BHRM, no período de 31 anos (1986 a 2016), observa-se que a média anual da precipitação para a bacia é de $1.072 \mathrm{~mm}$.

Conforme a Figura 10, o ano menos chuvoso do período analisado para a BHRM, foi 1993 (514mm), seguido por 1998 (641mm) e 1990 (644mm), respectivamente. Observa-se que todos eles fazem parte da década de 1990, é que contém a maioria dos anos secos do período, assim também pode confirmar que conforme afirma Marengo (2009), quando o autor escreve que a década de 1990 foi realmente a mais seca, não só para as regiões do Sul/Sudeste do Brasil mas também para o Norte/Nordeste.

Observando a Figura 10, nota-se que o ano mais chuvoso de toda a série foi $1986(1.637 \mathrm{~mm})$. Em seguida têm-se os anos $2000(1.612 \mathrm{~mm}) ; 2002$ $(1.578 \mathrm{~mm}) ; 1989(1.550 \mathrm{~mm})$ e $2010(1.535 \mathrm{~mm})$.
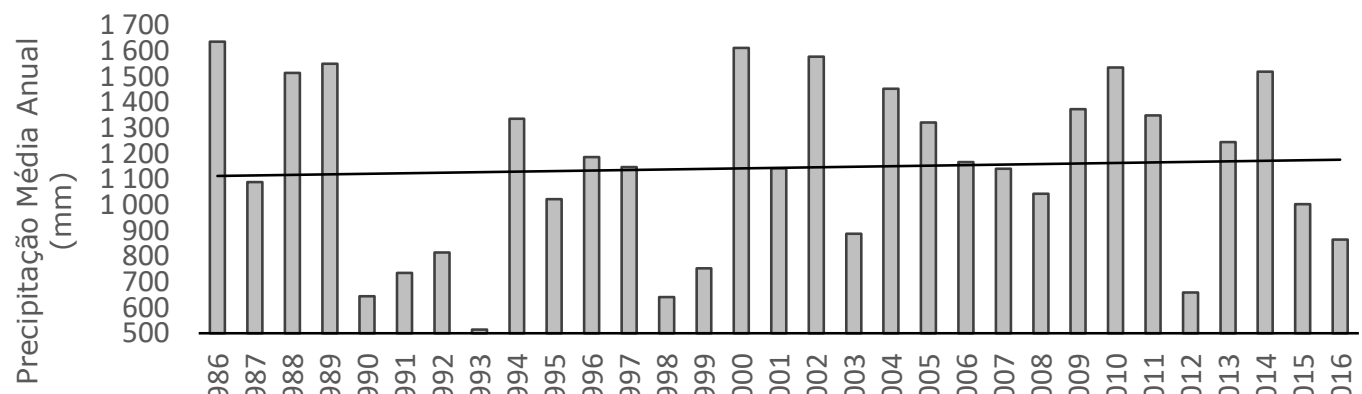

๒

Média Anual (mm)

— Tendência

Figura 10 - Precipitação Média Anual da BHRM (1986 a 2016).

Segundo Oliveira, Souza e Fragoso Jr. (2014), os anos de 1989, 2000 e 2010, foram anos onde ocorreram as cheias mais intensas na BHRM, causando óbitos e destruição de casas e atingindo 50.000; 76.000 e 157.124 pessoas, respectivamente.

Apesar do ano de 1986 ter sido o mais chuvoso, foi o ano de 2010 àquele que causou os maiores danos a população. Nesse sentido, torna-se importante analisar as condições de infiltração, drenagem, escoamento e retenção das 
águas pluviais da BHRM nesses anos, onde choveu bastante mais não causou cheias fortes.

Ainda sobre a Figura 10, observa-se uma leve tendência positiva de aumento das chuvas ao longo do tempo, não sendo no entanto, tão siginificativa, para ser considerada como uma mudança climática, seria necessário analisar uma série muito mais longa para afirmar isso.

Ao analisar o Índice de Anomalia da Chuva (IAC), percebemos algumas diferenças entre os resultados anteriores.

Conforme a Figura 11, o ano com anomalia negativa mais forte foi 1999, ano de La Niña Moderado (Tabela 2) e o que apresentou a maior anomalia positiva foi 2010, ano de El Niño Fraco (onde ocorreu a maior cheia que se tem registros na BHRM). Observa-se também que a segunda maior anomalia positiva ocorreu no ano de 2004 e em terceiro lugar 2001 (anos El Niño Fraco e Moderado respectivamente).

Tabela 2 - Ocorrências de ENOS entre 1986 à 2016.

\begin{tabular}{ll}
\hline \multicolumn{2}{c}{ Ocorrências de ENOS } \\
\hline Ocorrência de El Niño & Ocorrência de La Niña \\
\hline $1986-1988$ (Moderado) & $1988-1989$ (Forte) \\
$1990-1993$ (Forte) & $1995-1996$ (Fraco) \\
$1994-1995$ (Moderado) & $1998-2001$ (Moderado) \\
$1997-1998$ (Forte) & $2007-2008$ (Forte) \\
$2002-2003$ (Moderado) \\
$2004-2005$ (Fraco) \\
$2006-2007$ (Fraco) \\
$2009-2010$ (Fraco) \\
\hline
\end{tabular}

Fonte: http://enos.cptec.inpe.br/

É possível observar que as maiores anomalias negativas ocorreram na década de 1990 que dentre os 10 anos têm 7 abaixo da média, ou seja apenas 3 anos na década de 1990 superaram a média pluviométrica. A Tabela 2 mostra que nessa década houve mais ocorrências de El Niño do que de La Niña.

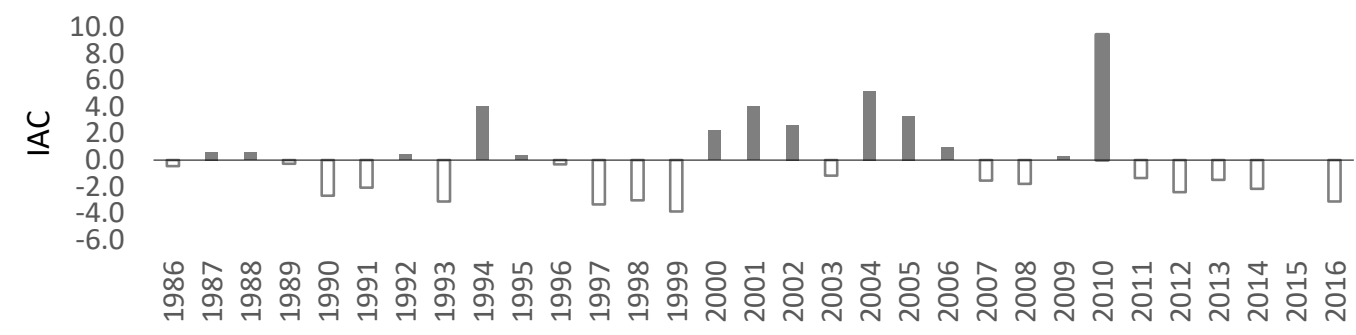

Anos

Figura 11 - Índice de Anomalia da Chuva da BHRM (1986 a 2016). 
Ao analisar a Figura 11, observa-se que há uma variabilidade decenal no regime pluviométrico. Enquanto a década de 1990 possui 7 anos abaixo da média, a década de 2000 é iversamente proporcional, ou seja, possui 7 anos acima da média, sendo portanto considerada um década chuvosa.

Conforme a análise dos resultados encontrados através do IAC para o perído de 1986 à 2016 (Figura 11), podemos observar que há alternâncias decenais no período de 7 à 10 anos, não se comprovando escalas maiores do que isso. Também observa-se, que há picos menores, geralmente na escala de 3 anos.

No IAC analisado para a BHRM, dos 31 analisados (de 1986 à 2016), têm-se 14 positivos e 17 negativos. Observa-se que apesar da maioria dos anos estarem abaixo da média para o período analisado, ainda assim, há uma leve tendência positiva no total, ou seja, é possível que eventos extremos estejam contribuindo para essa tendência.Já na década seguinte, a partir de 2010, observa-se uma redução da precipitação.

A Figura 11, também demonstra que além da variabilidade interanual também há uma variabilidade interdecenal, com perceptíveis alternâncias que em alguns anos, coincidem com as variações da ODP para o mesmo período, porém, em outros não. As varioções da ODP estão expostas na Figura 12:

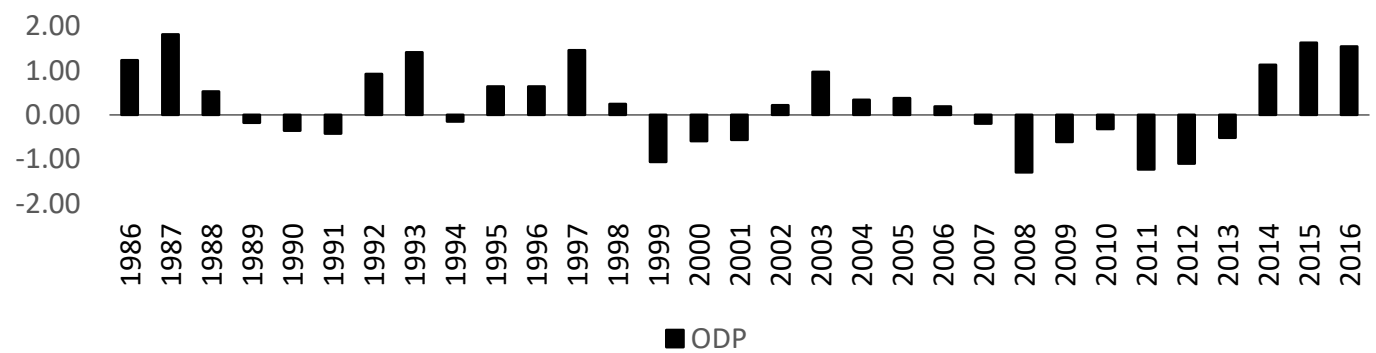

Figura 12 - Oscilação Decadal do Pacífico - ODP (1986 a 2016). Fonte: http://research.jisao.washington.edu/pdo/.

Na Figura 13, observa-se a relação do IAC com a ODP. Dos 31 anos analisados. Ao analisar todo o período, observa-se que conforme o IAC, ocorreram 17 anos secos na BHRM, assim como houve 17 anos em que a ODP apresentou dados positivos de Temperatura da Superfície do Mar (TSM), ou seja, a temperatura esteve acima da média, porém esses anos não são coincidentes de modo geral, na variabilidade interanual, como pode-se observar abaixo: 


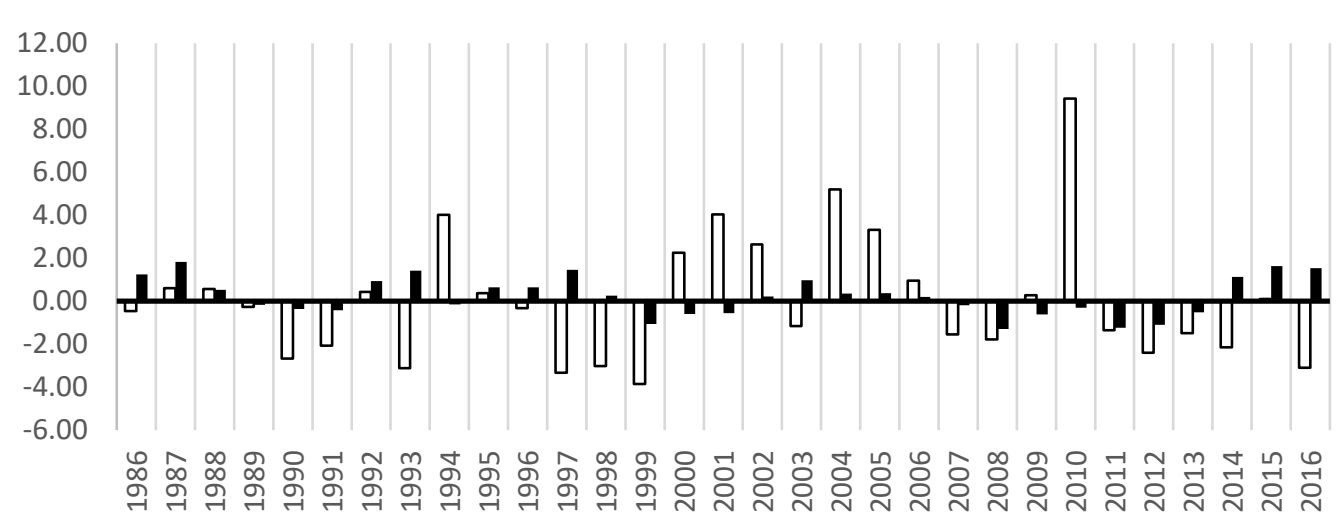

$\square I A C \square O D P$

Figura 13 - Relação entre o IAC e a ODP (1986 a 2016).

Ao analisar a figura 14, observa-se a correlação entre o IAC e a ODP. A correlação entre os dois valores, para o mesmo período se mostrou desprezível após a realização do cálculo do Coeficiente de Correlação de Pearson ( $r$, (BUSSAB \& MORETIN, 2017) onde $r=-0,09$, ou seja, existe uma pequena correlação inversamente proporcional, porém mínima e irrelevante. Isso demonstra que em escala interanual, o IAC da BHRM é pouco afetado pela ODP, mesmo que possua um total de anos secos, conforme a Figura 13, igual ao dos anos em que houve uma ODP positiva, não há correlação interanual.

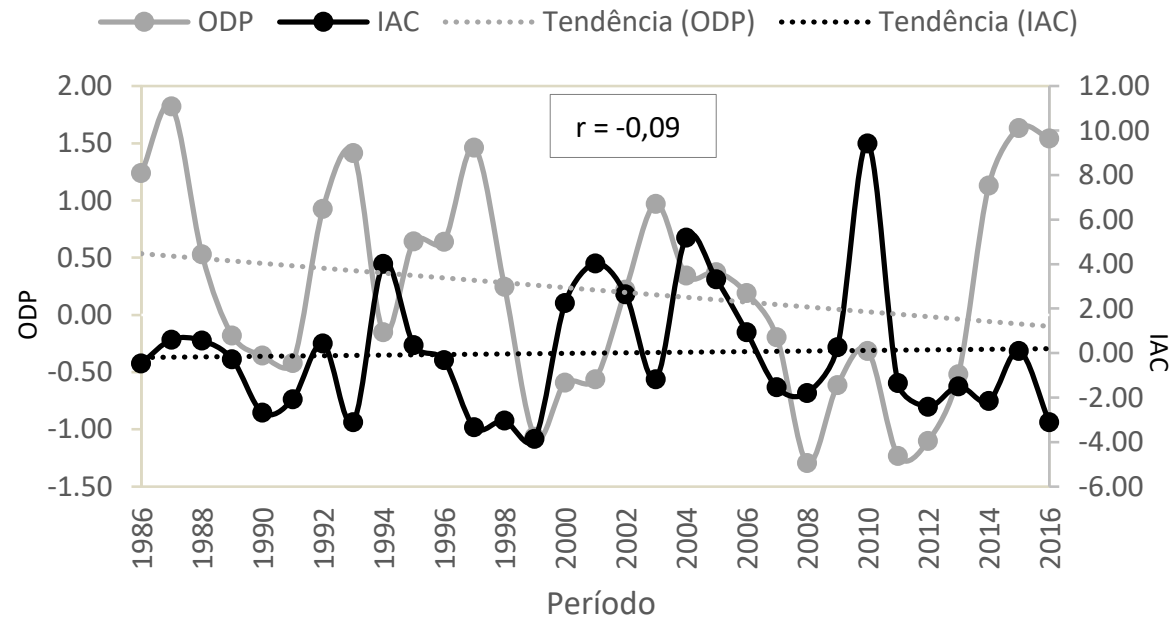

Figura 14 - Correlação entre o IAC e a ODP (1986 a 2016).

Na Figura 14, também é possível analisar que para o período estudado (1986 a 2016), houve uma tendência de redução da TSM do Pacífico, o que poderia provocar um aumento significativo das chuvas na BHRM, porém, esse 
aumento foi mínimo, quase desprezível. Isso demonstra que a influência da ODP na BHRM em escala interanual, é pouco relevante, tornando-se necessário correlacionar esses valores em outras escalas espaços-temporas, assim como averiguar outros sistemas climáticos e ambientais que podem estar tendo uma maior influência sobre a precipitação dessa bacia.

A variabilidade decenal ou multidecenal, é menos analisada do que a variabilidade interanual, segundo Kayano e Andreoli (2009), somente em fins dos anos 1980 foi notada esse tipo de fenômeno no Pacífico Norte, a partir de então vários trabalhos detectaram essas mudanças, tanto no Pacífico quanto no Atlântico, ainda segunda as autoras: "(...) procura-se esclarecer se a oscilação decenal no Pacífico Norte está relacionada ao ENOS, ou se é uma resposta linear ao ENOS."(KAYANO \& ANDREOLI, 2009. p. 377).

Essas variações, tanto no pacífico quanto no atlântico, não possuem uma alternância bem definida. Kayano \& Andreoli (2009), citam trabalhos de pesquisadores que observaram alternâncias em torno de 50 e 17 nos no Pacífico, assim como trabalhos que observaram alternâncias em ambos os lados do Atlântico Tropical, de 10 anos no norte e 14 anos no sul e através de análises espectrais encontraram ciclos de 9 anos (quase decenais), para a vazão dos rios Negro, Paraguai, Paraná e Uruguai, na América do Sul.

Como explicitado anteriormente há grandes diferenças geográficas (especialmente na pluviometria, vegetação e relevo) entre a parte setentrional da BHRM (PE) e a região meridional $(A L)$, tornando-se necessária a análise também entre essas duas regiões.

$\mathrm{Na}$ Figura 15, pode-se observar os resultados do IAC na parte pernambucana da BHRM. Conforme analisado, o ano mais seco em Pernambuco foi o ano de 1999 e o mais chuvoso 2010, o que coincide com o IAC geral da BHRM. Em Pernambuco dos 31 anos analisados houveram 16 anos acima da média e 15 abaixo da média, ou seja a maioria dos anos choveu acima do que se esperava, para esse período.

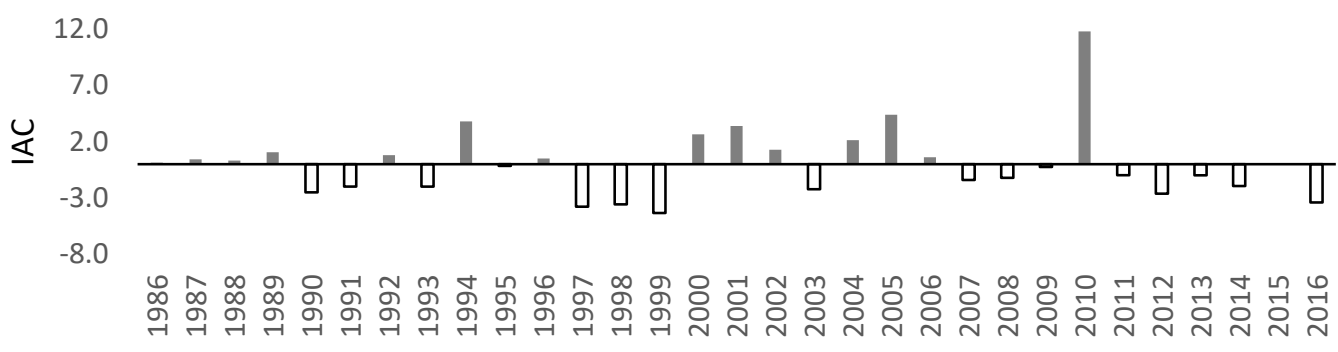

Anos

Figura 15 - Índice de Anomalia da Chuva para Pernambuco (1986 - 2016)

Já ao analisar o IAC das precipitações na parte alagoana da BHRM (Figura 16), observamos uma sensível diferença, sendo o ano mais seco 1993 (ano de El Niño Forte) e o mais chuvoso 2004 (ano de El Niño Fraco). 
É importante ressaltar que essa diferença do IAC mais elevado ser 2004 e não 2010, como em Pernambuco e na média geral da BHRM, possivelmente deve-se ao fato de que em 2010, devido a intensidade da enchente ocorrida na bacia, algumas estações hidrometeorológicas em Alagoas foram carreadas, comprometendo a média geral da pluviometria e da fluviometria (FRAGOSO JR, PEDROSA \& SOUZA, 2010).

Em Alagoas, dos 31 anos analisados, ocorreram apenas 13 acima da média (IAC positivo) e 18 abaixo da média (IAC negativo), o que de modo geral influenciou no IAC de toda a BHRM.

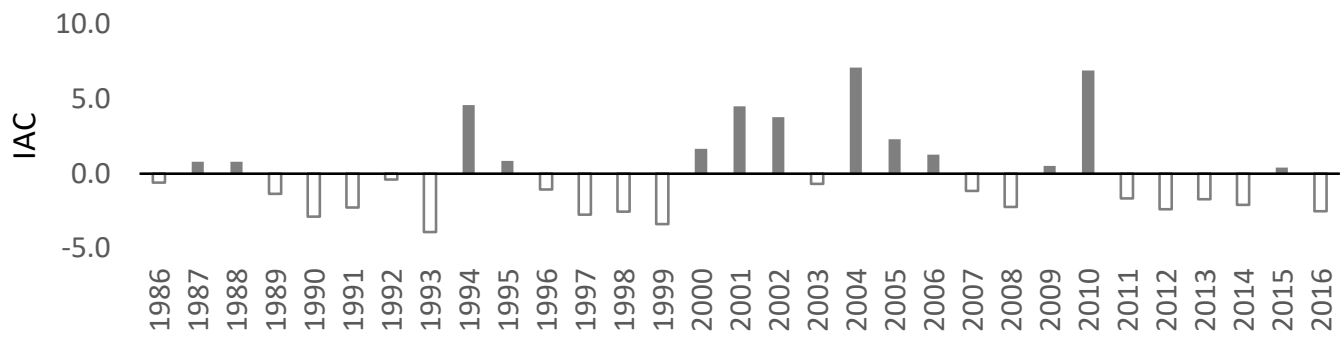

Anos

Figura 16 - Índice de Anomalia da Chuva para Alagoas (1986 a 2016)

De modo geral, tanto em Pernambuco quanto em Alagoas, os anos que obtiveram anomalias muito abaixo da média estão na década de 1990 e os que tiveram o IAC muito acima da média foram na década 2000. Ambos estão dentro da mesma variabilidade decenal dentre a década mais seca ou mais chuvosa da bacia.

\section{CONCLUSÕES}

A partir das observações de dados de 15 estações pluviométricas distribuídas ao longo de toda a BHRM (sendo nove em Pernambuco e seis em Alagoas) no período de 1986 a 2016, conclui-se o seguinte:

Os municípios que estão inseridos na parte meridional ( $A L)$ da BHRM, possuem maior precipitação média e total anual, enquanto que àqueles localizados na parte setentrional (PE), a precipitação é expressivamente menor, o que em conjunto com outros aspectos geográficos da bacia, justifica em parte, a escassez hídrica que ocorre ciclicamente nos municípios pernambucanos e as cheias que também ocorrem ciclicamente nos municípios alagoanos.

O município que apresentou a maior quantidade de chuva precipitada em todo o período foi Rio Largo $(A L)$, comprovou-se isso através da análise dos dados do posto 935060 (ANA), com valores de 1.910,32 mm de precipitação média e 59.219,86 mm de precipitação total para o período.

Em contrapartida, o município que apresentou menor quantidade de precipitação (média e total) para o período de 1986 a 2016 foi o município de 
Lajedo (PE), com valores de 521,86 mm de precipitação média e 12.524,60 para precipitação total do período.

São os meses de junho e julho os mais chuvosos e os meses de novembro e dezembro os mais secos para toda a BHRM, sendo abril, maio, junho e julho o quadrimestre mais chuvoso do ano e outubro, novembro, dezembro e janeiro o quadrimestre menos chuvoso.

O IAC de toda a BHRM, mostrou que o ano mais seco (maior anomalia negativa) foi 1999 e àquele mais chuvoso (maior anomalia positiva) foi o ano de 2010. O ano de 2010 foi aquele que teve a maior cheia da BHRM (durante o período analisado de 1986 a 2016), afetando 157.124 pessoas, destruindo e/ou danificando 32.851 casas e levando a óbito 46 pessoas (OLIVEIRA, SOUZA \& FRAGOSO JR., 2014).

Observou-se que na década de 1990, dos dez anos, sete ficaram abaixo da média, enquanto na década 2000, sete dos dez anos estiveram acima da média em toda a BHRM.

Pode-se afirmar que a precipitação da BHRM não recebe quase nenhuma influência do ENOS e da ODP em escala interanual.

Existe a possibilidade de estar ocorrendo um retardamento dos efeitos da ODP no IAC da BHRM, ou seja, a bacia pode estar sendo afetada apenas indiretamente ou cumulativamente pela ODP e/ou, haver influência preponderante de outros fenômenos climáticos com maior impacto na precipitação dessa bacia.

Observou-se também que dos 31 anos analisados em toda a BHRM, houve 14 com anomalias positivas (acima da média) e 17 com anomalias negativas (abaixo da média), assim como também ocorreram 17 anos com anomalia da ODP acima da média.

Apesar da maioria dos anos (do período analisado) se encontrarem abaixo da média, foi observado uma leve tendência de aumento das precipitações ao longo do tempo, essa tendência não é significativa para que se possa afirmar que houve mudança do clima da BHRM durante esse período, tornando-se necessário analisar um período muito maior.

Ressalta-se a dificuldade de obtenção de séries pluviométricas longas para essa bacia e a necessidade de se montar um banco de dados confiável e com contínua manutenção e análise.

\section{AGRADECIMENTOS}

Os autores agradecem à Agência Pernambucana de Águas e Clima (APAC), à Agência Nacional das Águas (ANA) e à Secretária de Meio Ambiente e Recursos Hídricos de Alagoas (SEMARH) pela disponibilização dos dados de precipitação. À Universidade Federal de Pernambuco (UFPE) pelo apoio institucional e à Coordenação de Aperfeiçoamento de Pessoal de Nível Superior (CAPES), pela concessão de bolsas de estudos a autora pós-graduanda. 


\section{REFERÊNCIAS BIBLIOGRÁFICAS}

ALVARES, C. A.; STAPE, J. L.; SENTELHAS, P. C.; DE MORAES, G. J. L.; SPAROVEK, G. Köppen's climate classification map for Brazil. Meteorologische Zeitschrift, Estugarda, Alemanha, v.22, n.06, p. 711-728, 2014.

ANDRADE, M. C. A Terra e o Homem no Nordeste. 8 Ed. São Paulo: Editora Cortez, 2005, 334 p.

ANDREOLI, R. V.; KAYANO, M. T.; GUEDES, R. L.; OYAMA, M. D.; ALVES, M. A. S. A influência da temperatura da superfície do mar dos oceanos Pacífico e Atlântico na variabilidade de precipitação em Fortaleza. Revista Brasileira de Meteorologia, São José dos Campos, v. 19, n. 3, p. 337-344, 2004.

ARAÚJO, L. E.; DA SILVA, D. Influência da variabilidade climática sobre a distribuição espaço-temporal da precipitação na região do baixo paraíba (PB). Revista Caminhos da Geografia. Uberlândia, v. 12, n.37, p. 289-304, 2015.

ARAÚJO, L. E.; MORAES NETO, J. M.; SOUSA, F. A. S. Análise climática da bacia do rio Paraíba - Índice de Anomalia da Chuva (IAC). Revista de Engenharia Ambiental, Espírito Santo do Pinhal, v. 06, n. 03, p. 508-523, 2009.

ÁVILA, P. L. R.; BRITO, J. I. B. Relação entre a Oscilação Decadal do Pacífico e a variabilidade de precipitação de Campina Grande, PB. Revista Ciência e Natura, Santa Maria, v. 37, n., p. 159-162, 2015.

BARBOSA, V. V.; SOUZA, W. M.; GALVİNCIO, J. D.; COSTA, V. S. O. Análise da variabilidade climática do município de Garanhuns, Pernambuco - Brasil. Revista Brasileira de Geografia Física, Recife, v. 09, n. 02, p. 353-367, 2016.

BUSSAB, W. O.; MORETIN, P. A. Estatística básica. 9 ed. São Paulo: Saraiva, 2017, 576 p.

BERTALANFFY, L. Teoria Geral dos Sistemas: fundamentos, desenvolvimento e aplicações. 8 ed. Petrópolis, RJ: Vozes, 2015, 360 p.

CHAGAS NETO, P.; ARAÚJO, L. E. Avaliação espaço-temporal da precipitação da microrregião do brejo paraibano. Revista Brasileira de Climatologia, Curitiba, v. 21, n. 13, p. 284-294, 2017.

CHRISTOFOLETTI, A. Modelagem de sistemas ambientais. 1 ed. São Paulo: Blucher, 1999, $236 \mathrm{p}$.

DA SILVA, D. F.; ARAúJO, L. E.; KAYANO, M. T.; SOUSA, F. A. S. Análise da precipitação na bacia do rio Mundaú usando o IAC. Revista UNOPAR, Curitiba, v. 07, n. 03, p. 53-61, 2008.

DA SILVA, D. F. Análise de aspectos climatológicos, agroeconômicos, ambientais e de seus efeitos sobre a bacia hidrográfica do Rio Mundaú (AL e PE). 2009. 218f. Tese (Doutorado em Recursos Naturais). Universidade Federal de Campina Grande, Campina Grande.

FERREIRA, P. S.; GOMES, V. P.; GALVÍNCIO, J. D.; SANTOS, A. M.; SOUZA, W. M. Avaliação da tendência espaço-temporal da precipitação pluviométrica em uma região semiárida do estado de Pernambuco. Revista Brasileira de Climatologia, Curitiba, v. 21, n. 13, p. 113-134, 2017.

FRAGOSO JR., C. R.; PEDROSA, V. D. A.; SOUZA, V. C. B. D. Reflexões sobre a cheia de junho de 2010 nas bacias do rio Mundaú e Paraíba. In: Simpósio 
Regional Brasileiro de Recursos Hídricos, 10., Fortaleza. 2010. Anais... Fortaleza: ABRH, 2010. 1 CD-ROM.

FRANÇA, E. M. S., SILVA, S. A. Influência da cobertura vegetal na vazão da parte alta do rio Mundaú, PE/AL. In: PEREZ FILHO, A.; AMORIM, R. R. (Orgs.). Os desafios da geografia física na fronteira do conhecimento. Campinas: Instituto de Geociências - UNICAMP, 2017. p. 7140 - 7151.

GOMES, D. D. M.; DE LIMA, D. R. M.; DUARTE, C. R.; VERÍSSIMO, C. U. V.; GOLDFARB, M. C. Análise e Compartimentação Moformétrica da Bacia Hidrográfica do Rio Mundaú - Pernambuco e Alagoas. Revista de Geologia, Fortaleza, v.27, n2, p.167-182, 2014.

GOMES, D. D. M. Geoprocessamento aplicado à análise e zoneamento dos sistemas ambientais da bacia hidrográfica do rio Mundaú - PE/AL. 2015. 231f. Tese (Doutorado em Geologia). Universidade Federal do Ceará, Fortaleza.

GOMES, D. D. M.; DE LIMA, D. R. M.; DUARTE, C. R.; VERÍSSIMO, C. U. V. Mapeamento e caracterização dos sistemas ambientais da bacia hidrográfica do Rio Mundaú - Pernambuco e Alagoas. Caderno de Geografia, Belo Horizonte, v.26, n2, p.272-299, 2016.

GONZALES, R. A.; ANDREOLI, R. V.; CANDIDO, L. A.; SOUZA, R. A. F. Influence of El Niño-Southern Oscillation and Equatorial Atlantic on rainfall over northern and northeastern regions of South America. Acta Amazônica, Manaus, v.43, n.4, 2013.

INPE. Últimas Ocorrências de El Niño e La Niña. Disponível em: < http://enos.cptec.inpe.br/ >. Acesso em 06 de maio de 2018.

IPCC, 2014: Climate Change 2014: Synthesis Report. Contribution of Working Groups I, II and III to the Fifth Assessment Report of the Intergovernmental Panel on Climate Change [Core Writing Team, R.K. Pachauri and L.A. Meyer (eds.)]. IPCC, Geneva, Switzerland, 169 pp.

KAYANO, M. T.; ANDREOLI, R. V. Decadal variability of northeast Brazil rainfall and its relation to tropical sea surface temperature and global sea surface pressure anomalies. Journal of Geophysical Research, V. 109, C11011, 2004.

KÖPPEN, W. Grundriss der Klima kunde: Outline of climate science. Berlin: Walter de Gruyter, 1931. 388 p.

MACHADO, P. J. O.; TORRES, F. T. P. Introdução à Hidrogeografia. São Paulo: Cengage Learning, 2012. 178p.

MARENGO, J.A.; ALVEZ, L. M.; ALVALA, R. C. S.; CUNHA, A. P.; BRITO, S.; MORAES, O. L. L. Climatic characteristics of the 2010-2016 drought in the semiarid Northeast Brazil region. Annals of the Brazilian Academy of Sciences. Ed. 90, págs. 1973-1885, 2018.

MARENGO. J. A.; DIAS, P. L. S. Mudanças climáticas globais e seus impactos nos recursos hídricos. In: REBOUÇAS, A.C.; BRAGA, B.; TUNDISI, J. G. (Orgs.) Águas Doces no Brasil: capital ecológico, uso e conservação. 3. ed. São Paulo: Escrituras, 2006, 748 p.

MOLION, L. C. B. Aquecimento global, El Niños, manchas solares, vulcões e oscilação decadal do Pacífico. Revista Climanálise, São José dos Campos, v.03, n. 01, 2005. 
NÓBREGA, R. S.; SANTIAGO, G, A, C, F.; SOARES, D. B. Tendências do controle climático oceânico sob a variabilidade temporal da precipitação no Nordeste do Brasil. Revista Brasileira de Climatologia, Curitiba, v. 18, n. 12, p. 276-292, 2016.

OLIVEIRA, D. L.; SOUZA, V. C. B.; FRAGOSO JR., C. R. Análise hidrológica da cheia excepcional ocorrida em junho de 2010 nas bacias dos rios Mundaú e Paraíba do Meio em Alagoas e Pernambuco. Revista Brasileira de Recursos Hídricos, Porto Alegre, v. 19, n. 03, p. 279-293, 2014.

PAREDES, F.J.; BARBOSA, A. Y.; GUEVARA, E. Análisis espacial y temporal de las sequías en el nordeste de Brasil. Agriscientia, Córdoba, v.32, n.01, 2015.

PEREIRA, M. L. T. SOARES, M. P. A.; SilvA, E. A.; MONTENEGRO, A. A. A.; SOUZA, W. M. Variabilidade climática no Agreste de Pernambuco e os desastres decorrentes dos extremos climáticos. Journal of Environmental Analysis and Progress, Recife, v.02, n.04, p.394-402. 2017.

RODRIGUES, L. O. SOUZA, W. M.; COSTA, V. S. O.; PEREIRA, M. L. T. P. Influência dos eventos El Niño e La Niña no regime de precipitação do Agreste de Pernambuco. Revista Brasileira de Geografia Física, Recife, v.10, n.06, p.1995-2009 2017.

ROOY, M.P. van. A Rainfall Anomaly Index Independent of Time and Space, Notes, v.14, p.43, 1965.

SILVA, R. O. B.; MONTENEGRO, S. M. G. L.; SOUZA, W. M. Tendências de mudanças climáticas na precipitação pluviométrica nas bacias hidrográficas do estado de Pernambuco. Revista de Engenharia Sanitária e Ambiental, Porto Alegre, v.22, n.3, p.579-589, 2017.

SILVA, S. A. SANTOS, C. C. Diagnóstico socioambiental de águas fluviais na região semiárida do nordeste brasileiro: estudo de caso do rio Canhoto em Canhotinho - PE. In: World Water Congress, 14., Porto de Galinhas. 2011. Anais... Porto de Galinhas: ABRH, 2011. 1 CD-ROM.

TUCCI, E. C. M. (Org.). Hidrologia: ciência e aplicação. 4 ed. Porto Alegre: Editora da UFRGS/ABRH, 2014, 943p.

TUCCI, E. C. M. Modelos hidrológicos. $2^{a}$ ed. Porto Alegre: Editora da UFRGS, 2005, 678p.

UVO, C. R. B.; REPELLI, C.; ZEBIAK, S. E.; KUSHNIR, Y. The relationships between Tropical Pacific and Atlantic SST and Northeast Brazil monthly precipitation. Journal of Climate, v.11, p. 551-562, 1998. 